\title{
Pitfalls of Impacted Ear Wax Removal in Developing Country, Nigeria
}

\author{
Waheed Atilade Adegbiji ${ }^{1}$, Shuaib Kayode Aremu ${ }^{2 *}$ and Abdul Akeem A Aluko ${ }^{3}$ \\ ${ }^{1}$ ENT Department, Ekiti State University Teaching Hospital, Ado Ekiti, Nigeria \\ ${ }^{2}$ ENT Department, Federal Teaching Hospital Ido-Ekiti, Ekiti State/Afe-Babalola University Ado-Ekiti, Nigeria
}

${ }^{3}$ ENT Department, Bayero University/ Aminu Kano Teaching hospital, Kano, Nigeria

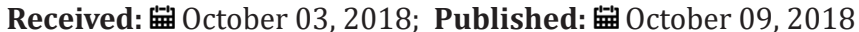

*Corresponding author: Shuaib Kayode Aremu, ENT Department, Federal Teaching Hospital Ido-Ekiti, Ekiti State/Afe-Babalola University Ado-Ekiti, Nigeria

\begin{abstract}
Background: Earwax impaction removal is one of the common otolaryngological procedures performed by general practitioner and nurses worldwide. This study aimed at determined the number, methods and complications of impacted earwax removal by general practitioner.

Material and method: It is cross sectional study of mode of impacted earwax removal in Lagos, Nigeria. Informed consent was obtained from the subject before enrollment. Structural questionnaire was administrated. Data obtained were statistically analyzed with SPSS version 18.

Result: Out of 349 subjects enrolled only 341 submitted valid result. Majority of the general practitioner saw an average of 5 cases of earwax impaction per month. Commonest mode of earwax removal is by using ceruminolytic agent followed by ear syringing. Failure of earwax removal is highest with use of ceruminolytic agent only followed by ceruminolytic agent with ear syringing $91.2 \%$ and $35.5 \%$ respectively.

Commonest ceruminolytic agent used in this study is cerumol. Commonest complication of earwax removal is $35.5 \%$ failure of earwax removal. Others were earache, vertigo and otitis externa.

Conclusion: Earwax impaction removal is common Ear, Nose and Throat procedure done by general practitioner. Their common mode of removal is by ceruminolyticagent only. This method account for the high cases of failure rate and major source of referral to otolaryngologist. Immersion of ceruminolytic agent with immediate ear syringing is effective and convenient for patients. This may also be less cost-effective than using eardrops and perhaps avoiding syringing.
\end{abstract}

Keywords: Earwax Impaction; General Practitioner; Ceruminolyticagent; Ear Syringing

\section{Introduction}

Earwax impaction occurs when it is symptomatic or prevents ear canal and tympanic membrane examination [1,2]. Annually earwax is responsible for about 12 million people consultation in the United States and 8 million earwax removal procedures [3]. Earwax impaction is one of the most common otologic conditions seen in primary care. Removing impacted earwax is the most common ear, nose, and throat procedure carried out in our community by general practitioner [4]. Often it causes unpleasant symptoms and present with hearing impairments, discomfort, itching and vertigo or asymptomatic [4-8]. It is common and serious sequel are hearing loss, social withdrawal, poor work function, ear injury from self-cleaning and so on [9]. It is major causes of primary care and secondary care consultation in ear, nose and throat clinic among the elderly people, mentally retarded people and infirm people $[1,9,10]$. There is still poor knowledge on the physiology, pathology, clinical significance and management of impacted earwax. So, there is a further need in the investigation of management of impacted cerumen [11]. Earwax impaction removal may be complicated with, trauma, bleeding, otitis externa, perforated eardrum and so on [9]. When the management of earwax impaction is comorbid with perforated eardrum, immune compromised patients and so on this may pose further problem the managing physician. 
Centuries ago clinicians have sought an effective means of removing impacted earwax. This ranges from earwax softening agent to facilitate removal, ear syringing, probing or surgery when appropriate $[8,12,13]$. All methods of earwax removal have their merit and demerit. Ear syringing is simpler, require few materials, less likelihood of tympanic membrane injury and require less skill compared to probing and surgical instrumentation. Ear syringing is the treatment of choice in primary health care centre. However, it could lead to, perforated tympanic membrane, otitis externa and soon. Probing and curettage require more skill but with fewer tendencies to ear infection. This study aimed at determining earwax impaction diagnosed per month, various method of earwax removal, and associated complication during earwax removal by general practitioner (Figure 1).

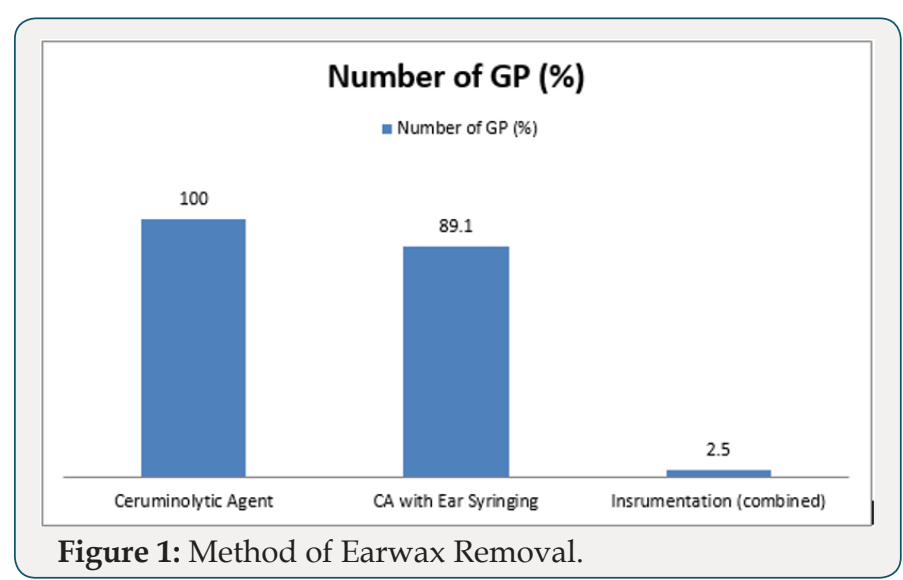

\section{Materials and Method}

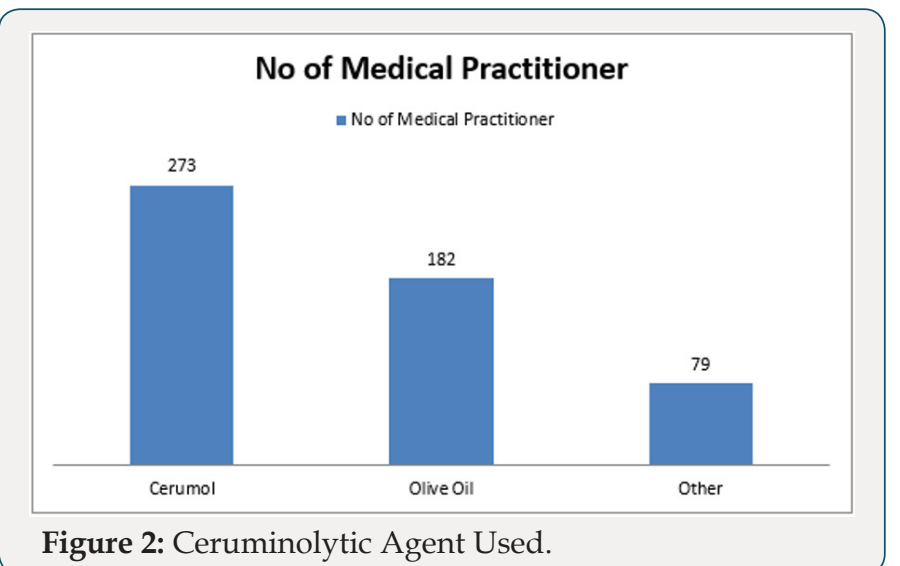

It is a cross sectional studies of general medical practitioner practicing in Lagos State, Nigeria, the commercial capital of Nigeria with population of over eighteen million inhabitants. Consent was obtained and given information was treated confidentially. Questionnaire was administered to the medical practitioner. Further information on earwax impaction method of removal, causes of failure of removal, associated complication in earwax removal and indication for patient referral to otorhinolarygologist. Inclusion criteria includes medical practitioner practicing in Lagos only, managing earwax impaction Exclusion criteria were nurses, otorhinolarygologist head and neck surgeon including resident doctors in Ear, Nose and Throat. Data obtained were collated and statistically analyzed SPSS version 18 (Figure 2).

\section{Results}

A total of 349 among general practitioners practicing in Lagos were enrolled into the study. Only 341 (97.7\%) responded. Majority saw and diagnosed an average of 5 cases of earwax impaction per month while minority saw and diagnosed greater than or equal to 16 cases of earwax impaction per month. Using earwax dissolving agent only was the most common method employed by the entire studied general practitioner while $2.3 \%$ attempt instrumentation. Commonest causes of failure of removal of earwax impaction is used of ceruminolytic agent only follows by ceruminolytic agent with ear syringing $91.2 \%$ and $35.5 \%$ respectively. Figure 2 shows commonly used ceruminolytic agent, $80 \%$ of cerumol account for the most commonly used ceruminolytic agent. Commonest complication following ear syringing is $35.5 \%$ failure to removal. Other complications were earache, vertigo, otitis externa and traumatic tympanic membrane perforation and were $21.1 \%$, $4.75,7.9 \%$ and 2.65 respectively. Impacted earwax removal were performed by $242(71.0 \%)$ nurses alone, 78 (22.8\%) nurses under supervision and $21(6.2 \%)$ by the general practitioner (Figure 3 ).

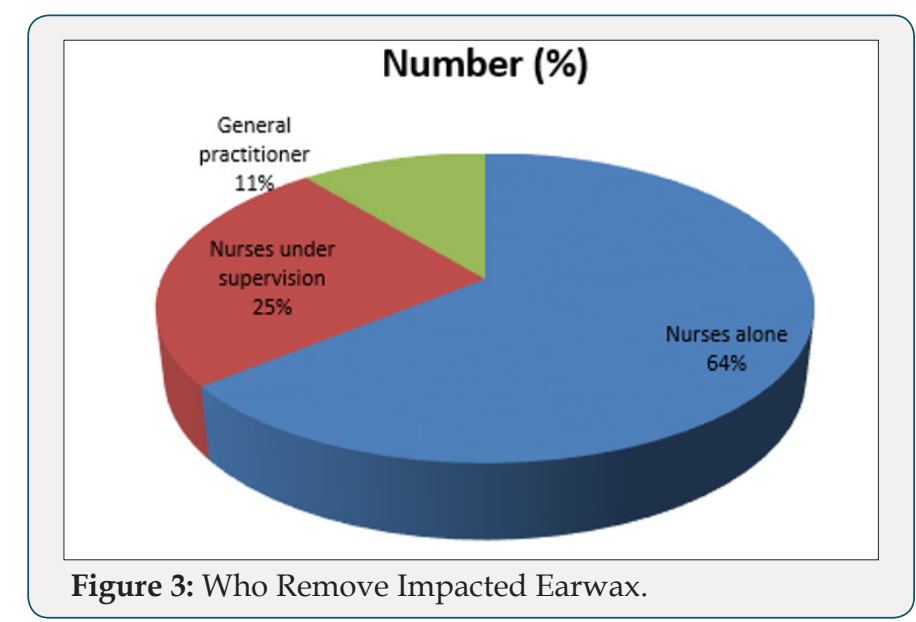

\section{Discussion}

Impacted earwax removal has been in practice since when ancient Egyptians syringed ear with olive oil and salt in patient with suppurating ear. Nowadays, the commonest otolaryngological procedure performed by general practitioner is earwax removal. This is one of the commonest sources of iatrogenic otolaryngological problem [14]. Experience of ear symptoms such as hearing loss, blockage, discomfort by patient prompted them to consult their family physician $[5,15]$. Occasionally some patient request for ear examination and removal of object or wax from their ear. In this study, an encouraging high response of $97.7 \%$ was observed from the studied group. This could be due to commoner nature of this condition with interesting management. This may also be due to continual patient request for earwax removal from their ear 
whenever they experience hearing impairments or blockage (Table 1). This is also a common request among many deaf patients. This is because of the misconception that earwax is pathological and that its accumulation blocks the ear subsequently leads to hearing loss, so it must be removed. Earwax impaction is removed by various methods which includes, ceruminolytic agent, ear syringing, instrumentation, and vacuuming, candling and surgical removal [16-21]. Earwax removal must be done by trained and skill hand. Most of this method are highly technical and are performed by skilled hand [22]. Limitation of various methods must be noted and application of appropriate method is necessary to avoid complications.

Table 1: Average numbers of earwax impaction diagnosis per month.

\begin{tabular}{|c|c|c|}
\hline $\begin{array}{c}\text { Number of Earwax } \\
\text { Impaction }\end{array}$ & $\begin{array}{c}\text { Number of } \\
\text { Practitioner }\end{array}$ & Percentage (\%) \\
\hline $0-5$ & 153 & 44.9 \\
\hline $06-10$ & 109 & 32 \\
\hline $11-15$ & 63 & 18.5 \\
\hline$\geq 16$ & 16 & 4.7 \\
\hline
\end{tabular}

Commonly used methods were ceruminolytic agent installation to soften and liquefied the earwax and help the ear fulfill its selfcleaning function. This method should be considered first-line treatment of earwax impaction [23]. It is very easy for patient to apply ceruminolytic agent at home and this could lead to its high prescription. Ear syringing is then recommended for its removal if it failed as seen in other studies15-17. In this study highest failure rate was observed with the use of ceruminolytic agent only. This failure rate was reduced with additional use of ear syringing. Inadequate application of earwax softening agents, lead to difficult ear syringing and further increase failure rate. In cases of failure of earwax removal with or without complications patients are expected to be referred to the secondary or tertiary centre for further otolaryngological review and management [24]. There are various available earwax softening agent such as olive oil, cerumol, wax sol, xerumenx, exterol and so on. In a comparative study $2 \%$ paradichlorobenzene emerged as the most superior ceruminolytic, closely followed by $10 \%$ sodium bicarbonate. $2.5 \%$ acetic acid was found to be moderately while normal saline emerged as the least effective ceruminolytic agent [25]. Cerumol application in this study was the commonest ceruminolytic agent prescribed by general practitioner to their patient. It is more expensive and less readily available than olive oil.

Ear syringing is a very common practice among $19 \%$ general practitioners3.However it is the treatment of choice for cerumen impaction and is effective and safe23. Like other surgical procedure, earwax removal by syringing is not free of complication (Table 2). Previous studies revealed common complications of ear syringing such as failure of earwax removal (29\%), otitis media (17\%), perforation of the ear drum (15\%), and trauma to the external auditory meatus (11\%) [15,26]. Findings in this study revealed failure of earwax removal, earache, vertigo, otitis externa and traumatic tympanic membrane perforation $[15,26]$. It is a safe procedure. But it must be done after proper training. Immediate syringing after application of ceruminolytic agent to soften hard impacted earwax is more effective than using eardrops only for several days and delaying or avoiding syringing [27].

Table 2: Complication of earwax removal by ear syringing.

\begin{tabular}{|c|c|c|}
\hline Complication & $\begin{array}{c}\text { Number of Medical } \\
\text { Practitioner }\end{array}$ & Percentage (\%) \\
\hline Failure & 121 & 35.5 \\
\hline Earache & 72 & 21.1 \\
\hline Vertigo & 16 & 4.7 \\
\hline Otitis externa & 27 & 7.9 \\
\hline $\begin{array}{l}\text { Traumatic Perforated } \\
\text { tympanic membrane }\end{array}$ & 9 & 2.6 \\
\hline
\end{tabular}

\section{Conclusion}

Earwax removal remains common otolaryngological procedure performed by general practitioner. Methods of removal are generally safe and have limited application. Identification of difficult cases, use of appropriate technique and referral of these difficult cases to higher skill hand is advised to avoid on toward outcome.

\section{References}

1. Hand C, Harvey I (2004) The effectiveness of topical preparations for the treatment of earwax: a systematic review. Br J Gen Pract 54(508): 862-867.

2. Roland PS, Smith TL, Schwartz SR, Rosenfeld RM, Ballachanda B, et al. (2008) Clinical practice guideline: cerumen impaction. Otolaryngol Head Neck Surg 139(3 Suppl 2): 1-21.

3. Aung T, Mulley GP (2002) Removal of ear wax. BMJ 325(7354): 27.

4. Rafferty J, Tsikoudas A, Davis BC (2007) Ear candling: Should general practitioners recommend it? Can Fam Physician. 53(12): 2121-2122.

5. Karlsmose B, Lauritzen T, Engberg M, Parving A (2001) A randomized controlled trial of screening for adult hearing loss during preventive health checks. Br J Gen Pract 51(466): 351-355.

6. Burkhart CN, Kruge MA, Burkhart CG, Black C (2001) Cerumen composition by flash pyrolysis-gas chromatography mass spectrometry. Otol Neurotol 22: 715-722.

7. Al Khabori M, Kumar S, Khandekar R (2007) Magnitude of impacted earwax in Oman, its impact on hearing impairment and economic burden of earwax on health services. Indian J Med Sci 61(5): 278-285.

8. McCarter DF, Courtney AU, Pollart SM (2007) Cerumen impaction. Am Fam Physician 75(10): 1523-1528.

9. Coppin R, Wicke D, Mehta R, Little P (2004) Management of earwax in primary care--postal survey of UK GPs and practice nurses. Fam Pract 21(4): 413-414.

10. Akinpelu V O, Amusa YB (2007) Otological diseases in Nigeria children. Int J ototinolarygol 7: p. 1.

11. Coppin R, Wicke D, Little P (2008) Earwax. Br J Gen Pract 58(549): 284.

12. Memel D, Langley C, Watkins C, Barbara Laue, Martin Birchall, et al. (2002) Effectiveness of ear syringing in general practice: randomised controlled trial and patients' experiences. Br J Gen Pract 52(484): 906911. 
13. Rambout J, Van Rijn PM (2001) M-meatoplasty: Results and patient satisfaction in 125 patients (199 ears) otol Neurotol 22(4): 457-460.

14. Schmiemann G, Kruschinski C (2009) Complication rate of out-patient removal of ear wax: systematic review of the literature. HNO 57(7): 713718.

15. Browning GG (2008) Ear wax. BMJ Clin Evid.

16. Guidi JL, Wetmore RF, Sobol SE (2014) Risk of otitis externa following manual cerumen removal. Ann Otol Rhinol Laryngol 123(7): 482-484.

17. Clegg AJ, Loveman E, Gospodarevskaya E, Harris P, Bird A, et al. (2010) The safety and effectiveness of different methods of earwax removal: a systematic review and economic evaluation. Health Technol Assess 14(28): 1-192.

18. Leong AC, Aldren C (2005) A non-randomized comparison of earwax removal with a 'do-it-yourself' ear vacuum kit and a Jobson-Horne probe. Clin Otolaryngol 30(4): 320-323.

19. Eekhof JA, De Bock GH, Le Cessie S, Springer MP (2001) A quasi randomised controlled trial of worker as a quick softening agent of persistent earwax in general practice. Br J Gen Pract 51(469): 635-637.
21. Singer AJ, Sauris E, Viccellio AW (2000) Ceruminolytic effects of decussate sodium: a randomized, controlled trial. Ann Emerg Med 36(3): 228-232.

22. Pothier DD, Nieuwoudt D (2007) Endoscopic dewaxing in the audiology department--the Bristol experience. Clin Otolaryngol 32(6): 462-464.

23. Poulton S, Yau S, Anderson D, Bennett D (2015) Ear wax management. Aust Fam Physician 44(10): 731-734.

24.Grossan M (2000) Safe, effective techniques for cerumen removal. Geriatrics 55(1): 80(83-86).

25. Nair P, Golhar S, Baisakhiya N, Deshmukh PT (2009) A comparative study of ceruminolytic agents. Indian J Otolaryngol Head Neck Surg 61(3): 185-192.

26. Bopat U, Nia J, Bance M (2001) Severe audio vestibular loss following ear syringing for wax removal. J laryngolotol 115(5): 410-411.

27. Propst EJ, George T, Janjua A, James A, Campisi P, et al. (2012) Removal of impacted cerumen in children using an aural irrigation system. Int ] Pediatr Otorhino laryngol 76(12): 1840-1843.

20. Lopex R (2002) What is the best treatment for impacted cerumen? J Fam Pract 51(2): 113-118.

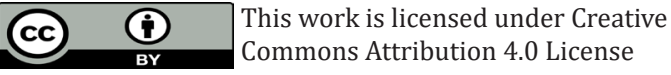

To Submit Your Article Click Here:

Submit Article

DOI: $10.32474 / \mathrm{SJO} .2018 .01 .000112$

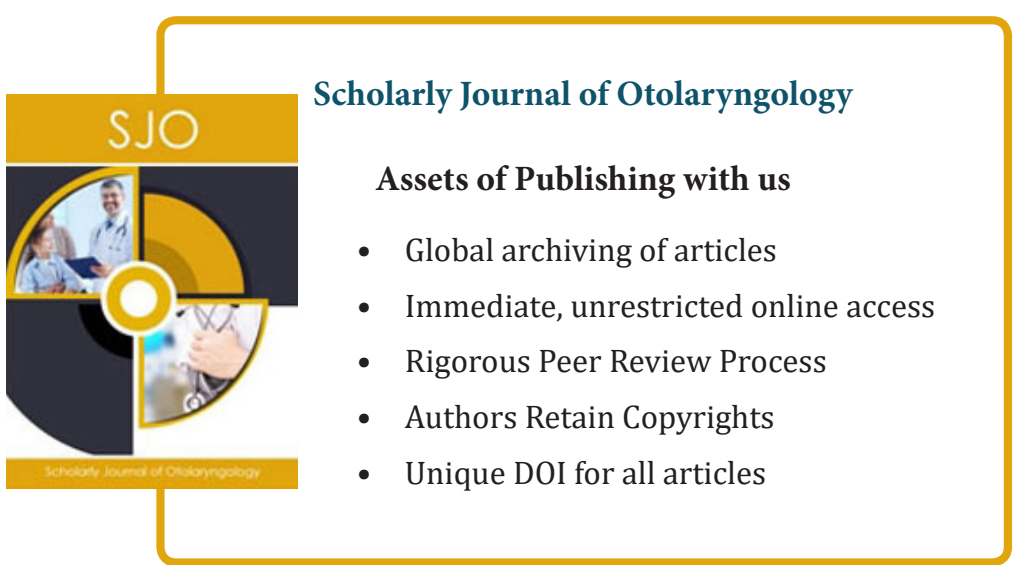

